\title{
Inhalt des XI. Bandes
}

\section{Germanistische Abtheilung.}

von Brünneck, W., Die Alfhebung der Leibeigenschaft durch dje Gesetzgebung Friedrichs des Grossen und das Allgemeine Preussische Landrecht (Fortsetzung und Schluss) 101

Brunner, Heinrich, Abspaltungen der Friedlosigkeit . . . . . 62

Liesegang, Zur Verfassungsgeschichte der Stadt Köln, vornehmlich im 12. und 13. Jahrhundert . . . . . . . . . 1 von Pflugk-Harttung, Zur Thronfolge in den germanischen Stammesstaaten . . . . . . . . . . . . . . 177

Wasserschleben, Ueber die Succession in Fuldische Lehne. . 151

\section{Litteratur:}

Platon, G., Le mallus ante theoda vel thunginum et le inallus legitimus. . . . . . . . . . . . . . . . . 206 Besprochen von Heinrich Brunner.

Finsen, V., Om den oprindelige Ordning af nogle af den islandske Fristats Institutioner . . . . . . . . . . 207 Besprochon ron Karl Lehmann.

Gaudenzi, Aug., Nuovi frammenti dell’ editto di Eurico . . 213 Besprochen von Arthur Schmidt.

Seignolıs, Ch., Le régime féodal en Bourgogne jusqu'en 1360. Étude sur la société et les institutions d'une Province française au moyen âge . . . . . . . . . . . . 225

Tholin, G., 1) Ville libre et Barons. Essai sur les limites de la Juridiction d'Ageu et sur la condition des forains de cette juridiction comparée à celles des tenanciers des Seigneurjes qui en furent détachées. 2) Cahiers et doléances du Tiers état du pays d'Agenais aux Etats généraux, 1588. 1614. 1649. 1789 . . . . . . . . . 227

Pouffin, Henry. Essay sur l'organisation et la Juridiction municipales au moyen àge . . . . . . . . . . . 228

Beaudouin, Edouard. La Participation des hommes libres au jugement dans le droit franc . . . . . . . . . . 231 
Rérolle, Lucien. Du Colonage partiaire et spécialement du métayage . . . . . . . . . . . . . . . 233

Prou, Maurice. Mannel de Paléographie latine et française du VI au XVII siècle . . . . . . . . . . . . . 234 Besprochen von König.

Günther, L., Die Idee der Wiedervergeltung in der Geschichte und Philosophie des Strafrechts . . . . . . . . . 235 Besprochen von Heinrich Brunuer.

Delbrück, Berthold, Die indogermanischen Verwandtschaftsnamen . . . . . . . . . . . . . . . . . . . 236 Besprochen von O, Gierke.

Endemamn, Studien in der romanisch-kanonischen Wirthschaftsund Rechtslehre bis gegen Ende des 17. Jahrhundejts. Zweiter Band . . . . . . . . . . . . . . . . 239 Besprochen von Kohler.

Lamprecht, Karl, Deutsches Wirthschaftsleben im Mittelalter . $\mathbf{2 4 2}$ Besprochen won R. Schröder.

Bei der Redaction eingegangene Werke. . . . . . . . . 251

\section{Miscellen :}

Zur nordgermanischen Auflassung. Von Karl Lehmanis . . 255

Ein Heidelberser Rechtsdenkmal. Von Georg Cohn . . . . 256

\section{Germanistische Chronik:}

Verhandlungen der Centraldirection der Monumenta Germaniae historica - 30. Plenarversammluug der Münchener historischen Commission - 8. Plenarversammlung der badischen historischen Commission - Johann Schlyter $\dagger$ - Richard John $\dagger$ - Julius Weizsäcker $\dagger-$ Wilhelm von Giesebrecht $\dagger-$ Wilhelm Müller $\dagger-$ Erwin Nasse $\dagger-$ Anton Niss $†-$ Joseph ron Held $†-$ Universitätsnachirichten 